Department of Neurology

$\mathrm{J}-\mathrm{J}$ Lin

Department of Pathology,

Tri-Service General Hospital and National Defense Medical Center, Taipei,

Taiwan, Republic of China

H-J Harn

Correspondence to:

Dr Juei-Jueng Lin,

Department of Neurology,

Tri-Service General

Hospital No 8, Sec 3, Ting-

Chow Road, 107, Taipei,

Taiwan, Republic of China.

Received 20 December 1994 and in revised form

30 March 1995

Accepted 12 April 1995

\section{Application of the polymerase chain reaction to monitor Mycobacterium tuberculosis DNA in the CSF of patients with tuberculous meningitis after antibiotic treatment}

\author{
Juei-Jueng Lin, Horng-Jyh Harn
}

\begin{abstract}
The polymerase chain reaction (PCR) was used to detect Mycobacterium tuberculosis DNA in 29 CSF specimens from seven patients with tuberculous meningitis after the start of antituberculous chemotherapy. Ten of the 13 CSF specimens taken from these patients with an initial treatment of three weeks were positive for the PCR study. By contrast, only one of the other 16 CSF specimens taken from patients treated for more than three weeks was positive. This study shows that $M$ tuberculosis DNA can exist in the CSF of a patient with tuberculous meningitis for three weeks after treatment and that PCR can still be a sensitive method to detect $M$ tuberculosis DNA in the CSF after the start of treatment in patients with tuberculous meningitis.
\end{abstract}

\author{
$(\Im$ Neurol Neurosurg Psychiatry 1995;59:175-177)
}

Keywords: antituberculous chemotherapy; Mycobacterium tuberculosis; polymerase chain reaction; tuberculosis meningitis

Early accurate diagnosis of tuberculous meningitis remains a challenge with conventional methods. A method of polymerase chain reaction (PCR) based on DNA amplification has the sensitivity to detect small numbers of mycobacteria present in clinical specimens $^{12}$ and has proved to be the most sensitive method for an accurate diagnosis of patients with tuberculous meningitis. ${ }^{3-8}$ Although studies have successfully applied PCR for the diagnosis of patients with tuberculous meningitis, using this method to monitor Mycobacterium tuberculosis DNA in the CSF of patients with tuberculous meningitis after the start of antituberculous treatment has not yet been established.

Table 1 CSF studies and clinical outcome of patients with tuberculous meningitis

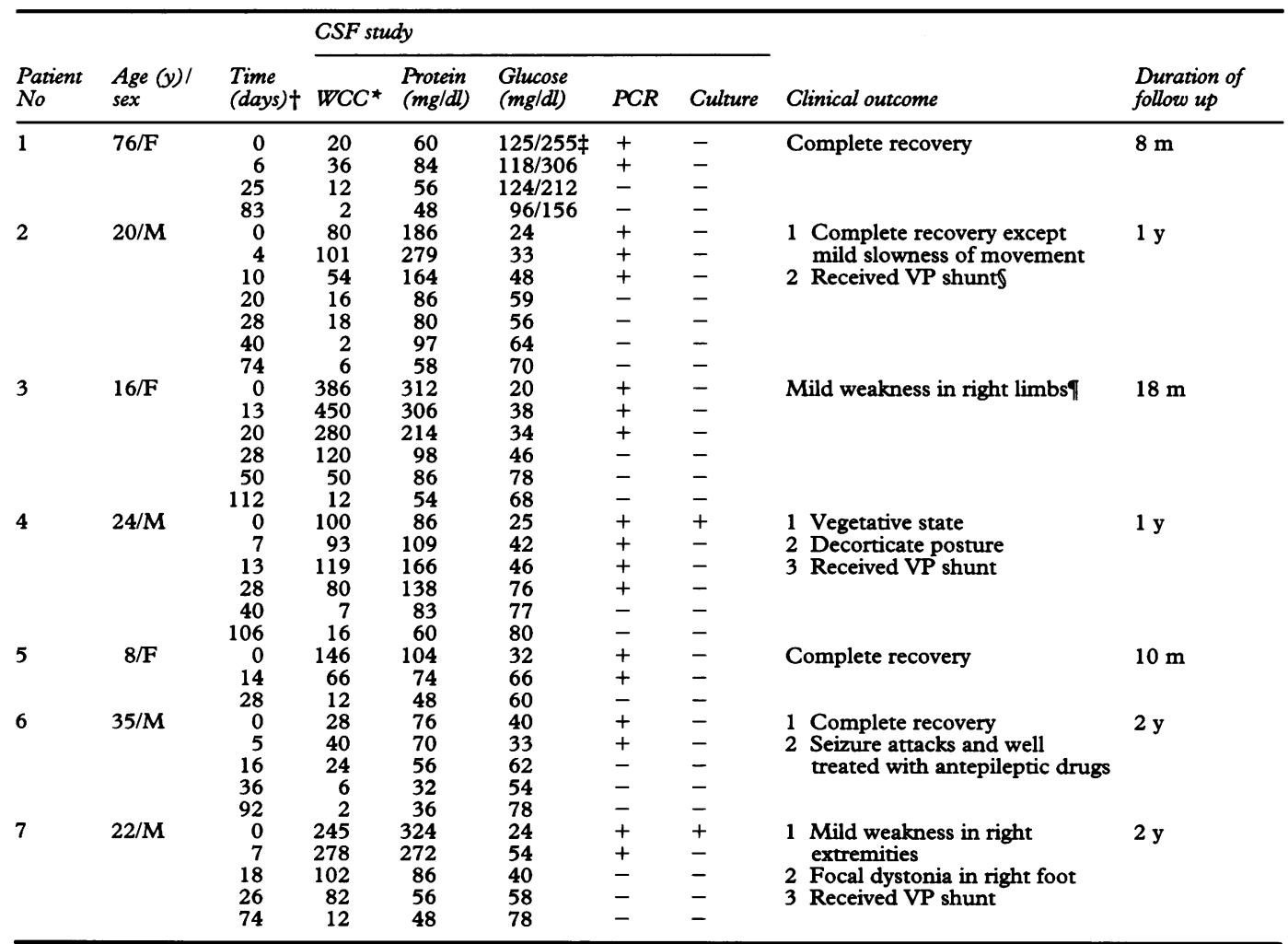

*WCC = white cell count/mm $;$; time CSF samples were taken from patients with tuberculous meningitis after the start of treatment. Day 0 means the CSF samples were taken from patients before treatment; $¥$ CSF glucose/blood glucose; \acute hydrovasculitis. 
Table 2 Results of applying the polymerase chain reaction to monitor M tuberculosis DNA in the CSF of patients with tuberculous meningitis, after the start of treatment

\begin{tabular}{llll}
\hline \multirow{2}{*}{$\begin{array}{l}\text { Time of CSF sampling } \\
\text { after treatment }\end{array}$} & \multicolumn{2}{l}{$P C R$ result } & \\
\cline { 2 - 3 } & Positive & Negative & Total \\
\hline <3 weeks & $10(78 \%)$ & 3 & 13 \\
3-6 weeks & 1 & 8 & 9 \\
>6 weeks & 0 & 7 & 7 \\
Total & $11(38 \%)$ & 18 & 29 \\
\hline
\end{tabular}

\section{Materials and methods}

In our previous report, ${ }^{8}$ we prospectively applied PCR to detect $M$ tuberculosis DNA in CSF specimens taken from 18 patients with clinically suspected tuberculous meningitis. Results showed that PCR was positive in 14 . After the start of antituberculous treatment, we repeatedly sampled CSF specimens from these 14 patients with PCR positives at an irregular time to monitor the existence of $M$ tuberculosis DNA. Four out of the 14 patients refused lumbar puncture again after the treatment, two were lost to follow up, and one died of sepsis. This study included seven patients with 29 CSF specimens (table 1).

Methods of extraction of DNA from CSF specimens, designation of primers, and procedures of PCR and Southern blot hybridisation were carried out as described in our previous publication. ${ }^{8}$ A sample was regarded as positive when DNA with a molecular weight expected for the amplified product (240 base pairs) was seen on autoradiography. Each CSF specimen was tested at least twice in different batches with the same procedures to assure the reproducibility of the results.

\section{Results}

This study showed that PCR could detect $M$ tuberculosis DNA in 11 of 29 CSF specimens taken from these seven patients after the start of treatment. Ten of the 11 PCR positive CSF specimens were taken from patients with an initial treatment of three weeks (13 CSF specimens, $78 \%$; table 2). Another PCR positive CSF specimen was taken from one patient on the 28 th day after treatment. Specimens taken from patients with treatment of more than six weeks were all negative.

Table 1 summarises the detailed data of CSF specimens and outcome. Mycobacterial cultures of the $29 \mathrm{CSF}$ specimens were all negative despite the fact that two patients (4 and 7) had positive CSF cultures of their specimens before the start of treatment. None of the CSF samples was positive by direct smear (Ziehl-Neelsen's stain). Each patient had, however, received antituberculous chemotherapy consisting of at least a triple regimen of isoniazid, rifampicin, and pyrazinamide (or ethionamide). As well as the triple regimen, patients 6 and 7 had also received streptomycin. Outcomes of six patients were good after follow up for eight months to two years, four patients with complete resolution and two with residual mild neurological deficits. One was in a vegetative state.

\section{Discussion}

The PCR has been used to define novel diagnostic and epidemiological data for neurological diseases based on the fact that the method is rapid, accurate, and non-invasive. ${ }^{9}$ For identification of mycobacterial DNA in CSF specimens, PCR has proved to be the most sensitive method for an accurate diagnosis of tuberculous meningitis. ${ }^{3-8}$ Nevertheless, PCR assay has problems, especially when dealing with samples containing small amounts of mycobacterial bacilli. The study of Hance et al showed that when using hybridisation with a ${ }^{32} \mathrm{P}$-labelled oligonucleotide, the sensitivity of the application of PCR for detection of $M$ tuberculosis DNA in clinical specimens could be improved. ${ }^{1011}$ Some studies showed that a nested PCR protocol could also improve the sensitivity of detecting mycobacterial DNA in clinical specimens. ${ }^{61213}$ The study of Ostergaard et al, however, showed that Southern hybridisation on the nested PCR product did not give further PCR positive results. ${ }^{14}$ Therefore, regarding sensitivity, the nested PCR is superior to Southern hybridisation for the detection of $M$ tuberculosis DNA in CSF specimens, due to fact that nested PCR is simpler and less time consuming. Because the detection of mycobacterial DNA in our previous report was done by PCR after Southern hybridisation, ${ }^{8}$ we therefore still used the same method in this study to have the advantage of a comparison between the sensitivity of PCR in detecting $M$ tuberculosis DNA in the CSF of patients with tuberculous meningitis before and after antituberculous treatment.

After the start of treatment, mycobacterial cultures of CSF in patients with tuberculous meningitis rarely yield a positive result, ${ }^{15}$ which was the same as found in our study. Yet our study showed that PCR could persistently detect $M$ tuberculosis DNA in the CSF of patients with tuberculous meningitis within the initial three week treatment period. After treatment for more than three weeks, the PCR rarely yielded a positive result. Because treatment was effective in this study (as shown by radiology and the resolution of clinical symptoms), the persistent presence of $M$ tuberculosis DNA in CSF may indicate that antituberculous treatment induces the release of mycobacterial DNA in CSF. This persistence of positive PCR results was also found in patients with neurosyphilis in whom Treponema pallidum DNA was detectable in the CSF several months after effective treatment $^{18}$ and patients with cerebral toxoplasmosis in whom Toxoplasma gondii in the blood could also be detected for up to 12 days after initiation of treatment. ${ }^{19}$

When compared with our previous report, ${ }^{8}$ this study does not indicate a significant difference of PCR sensitivity for applying the method to detect $M$ tuberculosis DNA in the 
CSF of patients with tuberculous meningitis before treatment $(70 \%$ of sensitivity) and after an initial treatment of three weeks $(78 \%$ of sensitivity). The sensitivity of applying PCR to detect $M$ tuberculosis DNA in the CSF of patients with tuberculous meningitis having the initial treatment for three weeks is also similar to that of other studies. ${ }^{3-8}$ Therefore, we advise that it is still valuable to apply PCR in patients with clinically suspected tuberculous meningitis who promptly receive a diagnostic antituberculous trial.

This study was supported in part by a National Science Council Research Grant of the republic of China (NSC 83-0412-B-016-050). We are indebted to Miss Hui-Chin Chen and Miss Man-Ch'ing Tang for their expertise in technical support.

1 Brisson-Noël A, Gicquel B, Lecossier D, Levy-Frébault V, Nassif X, Hance A. Rapid diagnosis of tuberculosis by amplification of mycobacterial DNA in clinical samples. Lancet 1989;ii:1069-77.

2 Brisson-Noël A, Aznar C, Chureau C, et al. Diagnosis of tuberculosis by DNA amplification in clinical practice evaluation. Lancet 1991;338:364-6.

3 Kaneko K, Onodera O, Miyatake T, Tsuji S. Rapid diagnosis of tuberculous meningitis by polymerase chain nosis of tuberculous meningitis by polym
reaction (PCR). Neurology 1990;40:1617-8.

4 Shankar P, Manjunath N, Mohan KK, et al. Rapid diagnosis of tuberculous meningitis by polymerase chain reaction. Lancet 1991;337:5-7.

5 Donald PR, Victor TC, Jordaan AM, Schoeman JF, ven Helden PD. Polymerase chain reaction in the diagnosis of tuberculous meningitis. Scand $\mathcal{F}$ Infect Dis 1993;25: 613-7.
6 Liu PYL, Shi ZY, Lau YJ, Hu BS. Rapid diagnosis of tuberculous meningitis by a simplified nested amplification protocol. Neurology 1994;44:1161-4.

7 Folgueira L, Delgado R, Palengue E, Noriega A Polymerase chain reaction for rapid diagnosis of tuberculous meningitis in AIDS patients. Neurology 1994;44: 1336-8.

8 Lin JJ, Harn HJ, Hsu YD, Tsao WL, Lee HS, Lee WH. Rapid diagnosis of tuberculous meningitis by polymerase chain reaction assay of cerebrospinal fluid f Neurol 1995;242:147-52.

9 Darnell RB. The polymerase chain reaction: application to nervous system disease. Ann Neurol 1993;34:513-23.

10 Hance AJ, Grandchamp B, Levy-Frebault, V, et al. Detection and identification of mycobacteria by amplification of mycobacterial DNA. Mol Microbiol 1989;3: 843-9.

11 Brisson-Noël A, Aznar C, Chureau C, et al. Diagnosis of tuberculosis by DNA amplification in clinical practice evaluation. Lancet 1991;338:364-6.

12 Miyazaki Y, Koga H, Kohno S, Kaku M. Nested polymerase chain reaction for detection of Mycobacterium tuberculosis in clinical samples. F Clin Microbiol 1993; tuberculosis

13 Narita M, Matsuzono Y, Shibata M, Tagashi T. Nested amplification protocol for the detection of $\mathrm{Myco}$ bacterium tuberculosis. Acta Paediatr Scand 1992;81: 997-1001.

14 Ostergaard L, Nielsen AK, Black FT. DNA amplification on cerebrospinal fluid for diagnosis of cerebral toxoplasmosis among HIV-positive patients with signs or symptoms of neurological disease. Scand $\mathcal{F}$ Infect Dis 1993;25:227-37.

15 Kennedy DH, Fallon RJ. Tuberculous meningitis. $\mathcal{F} A M A$ 1979;24:264-8.

16 Noordhoek GT, Wolters FC, de Jonge MEJ, Van Embden JDA. Detection by polymerase chain reaction of Treponema pallidum DNA in cerebrospinal fluid from neurosyphilis patients before and after antibiotic treatment. F Clin Microbiol 1991;29:1976-84.

17 Dupouy-Camet J, de Souza SL, Maslo C, et al. Detection of Toxoplasma gondii in venous blood form AIDS patients by polymerase chain reaction. $\mathcal{f}$ Clin Microbiol 1993;31:1866-9. 